\title{
Intravascular Papillary Endothelial Hyperplasia: A Rare Vascular Lesion Affecting Submandibular and Sublingual Region
}

\author{
Zhenq Xu1, Li Long1, Jianch Zhang1, Ruiy Chen², Nan Yang ${ }^{3}$, Ping Zhang1 ${ }^{*}$ \\ ${ }^{1}$ Department of Oral and Maxillofacial Surgery, Tianjin Stomatology Hospital of Nankai University, Tianjin, \\ China \\ ${ }^{2}$ Department of Oral Pathology, Tianjin Stomatology Hospital of Nankai University, \\ Tianjin, China \\ ${ }^{3}$ Department of Nursing, Tianjin Stomatology Hospital of Nankai University, Tianjin, China \\ Email: xuzhenqi2001@163.com
}

Received 9 July 2014; revised 25 August 2014; accepted 9 September 2014

Copyright (C 2014 by authors and Scientific Research Publishing Inc.

This work is licensed under the Creative Commons Attribution International License (CC BY).

http://creativecommons.org/licenses/by/4.0/

(c) (i) Open Access

\begin{abstract}
Intravascular papillary endothelial hyperplasia is an unusual benign vascular lesion of the skin and subcutaneous tissue consisting of papillary formations lined with proliferative endothelial cells. The clinical characteristic is not specific and the diagnosis is based on histological examination. The lesion is often mistaken for angiosarcoma and a group of other benign and malignant vascular lesions. IPEH has been relatively rarely described in the head and neck region. An uncommon case located in the submandibular and sublingual region is presented which was misinterpreted as venous malformations and malignant tumors of vascular origin initially. A surgical excision was performed and no recurrences have been found after 5 years of follow-up.
\end{abstract}

\section{Keywords}

Intravascular Papillary Endothelial Hyperplasia, Submandibular and Sublingual Region, Angiosarcoma, Venous Malformation

\footnotetext{
*Corresponding author.
}

How to cite this paper: Xu, Z., Long, L., Zhang, J., Chen, R., Yang, N. and Zhang, P. (2014) Intravascular Papillary Endothelial Hyperplasia: A Rare Vascular Lesion Affecting Submandibular and Sublingual Region. Open Journal of Stomatology, 4, 470-474. http://dx.doi.org/10.4236/ojst.2014.49063 


\section{Introduction}

In 1923, Masson described a case of a 68-year-old man with an ulcerated hemorrhoid that could not be reduced. Masson noticed that the internal lining of the large veins sprouted papillae that filled the lumen of the vein and were covered by endothelium which he named "hemangioendotheliome vegetant intravasculaire". Later the terms endovascularite proliferante thrombopoietique, intravenous atypical vascular proliferation, intravascular angiomatosis, intravascular endothelial proliferation, Masson’s pseudoangiosarcoma and Masson's lesion have been adopted. In 1976, Clearkin and Enzinger coined the term intravascular papillary endothelial hyperplasia (IPEH) which seems to be more descriptive and less confusing and is the most frequently used in the English literatures obtained [1].

IPEH is an unusual benign non-neoplasm especially rarely found in head and neck region comprising approximately $2 \%$ of the vascular tumors of the skin and subcutaneous tissue. Clinically IPEH often represents as a firm or sometimes tender nodule or mass with slight elevation, rather sharp demarcation and slow growth characterised by red or blue discolouration of the overlying skin or mucosa. Pathologically IPEH is characterized by papillary fronds lined by proliferating endothelium within a vascular lumen [1] [2].

The main significance of IPEH is its clinical and microscopic resemblance to angiosarcoma and its possible misinterpretation as vascular malformations or mucocele [1] [3] [4]. In this article, we report an uncommon case affected the right submandibular and sublingual space which was misdiagnosed as venous malformations and malignant vascular tumors initially.

\section{Case Report}

A 39-year-old female was referred to our department regarding a 2-month history of recurrent slight-painful swelling on the right side of her neck below the mandible. 2 months ago she was consulted at the local community hospital with a sudden swelling of right submandibular region. The patient under the clinical diagnosis of lymphadenitis was given penicillin 4 million U twice a day through intravenous infusion, the swelling subsided two days later. She was asymptomatic until 2 weeks later when she complained of a recurrent right submadibular swelling. The local surgeon made an incision biopsy which showed microscopically plumps of endothelial cells in a dilated vessel (Figure 1(A)), the lesion was diagnosed as venous malformation. An intratumoral Pingyangmycin was performed. She was admitted to our faculty in July 2009 because of aggravated right submadibular swelling.

Clinical examination showed a firm rigid, non-sharped, non-pulsatile mass measuring $4 \mathrm{~cm} \times 3 \mathrm{~cm}$ affecting the region of right submadibular and sublingual mouth floor. Extraoral findings revealed that lesion was adhered to the inner surface of mandible bone with poor mobile, but the overlying skin was normal. Clinical intraoral examination of the mucosa of the right mouth floor showed slight reddish without discoloration reaction. There was no contribution of her general medical history, and the head and neck examination revealed no evidence of adenopathy, paresthesia, or motor nerve deficiency. The initial diagnosis of our faculty was malignant diseases of vascular origin, such as angiosarcoma or hemangioendothelioma, however, after 3 days' use of Cefmetazole 1 $\mathrm{g}$ bid ivd, there was significant decrease in the right submandibular swelling, a boundary-clear rigid moblie mass approximately $2.5 \mathrm{~cm}$ in diameter was touched. A Magnetic Resonance Imaging (MRI) scan which showed a mass in the right submandibular and sublingual space was obtained. The mass was clearly separated from the submandibular gland and other surrounding tissue. The lesion was low in density in an axial T1 weighed MR image and mixed high-low in density in an axial T2-weighed MR image (Figure 2).

The clinical and imaging features are quite different from venous malformation or malignant vascular lesions. Diagnosis was important for treatment. An incision biopsy at our department was performed intraorally and the material was submitted for histological examination consultation. Microscopically the most predominant feature of the lesion was the presence of papillary projections lined by endothelial cells without nuclear atypia, hyperchromasia, mitotic figures or necrosis within expanded blood vessels. In the adjacent areas, organizing thrombus was observed, however, invasion of surrounding tissues was not observed (Figure 1(B)). On the basis of the above characteristics, a diagnosis of Intravascular Papillary Endothelial Hyperplasia (IPEH) was made.

According to literatures gained, surgical removal of the mass was indicated and performed. A submandibular and intraoral approach was used to gain access to the lesion, and a well encapsulated vascular mass was encountered beneath the superficial layer of deep cervical fascia (Figure 3). The patient's postoperative course was uneventful. Five years after the surgery there were no symptoms or any evidence of recurrence. 

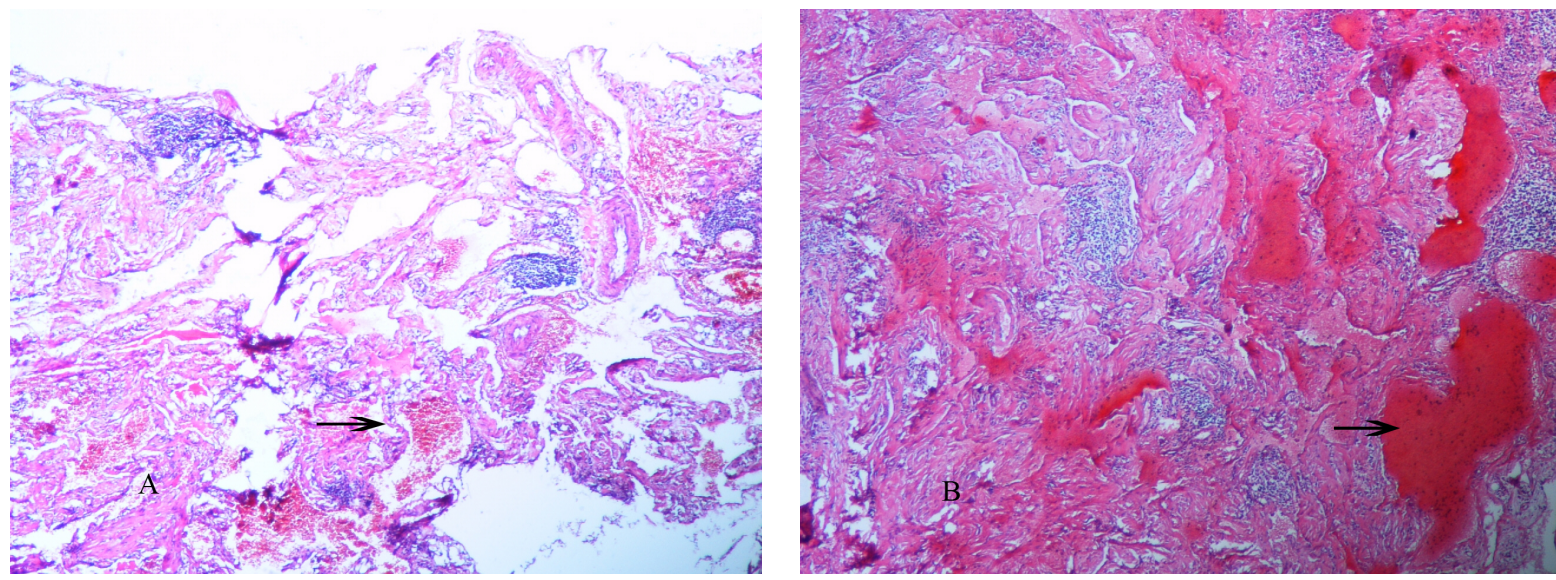

Figure 1. The biopsy gained at local community hospital (A) showed microscopically plumps of endothelial cells in a dilated vessel (H \& E stain, original maginification 100×); biopsy made in our faculty (B) showed papillary fronds lined by endothelial cells without nuclear atypia, hyperchromasia, mitotic figures or necrosis within expanded blood vessels, thrombis was observed (as arrow indicated, H \& E stain, original maginification 100×).
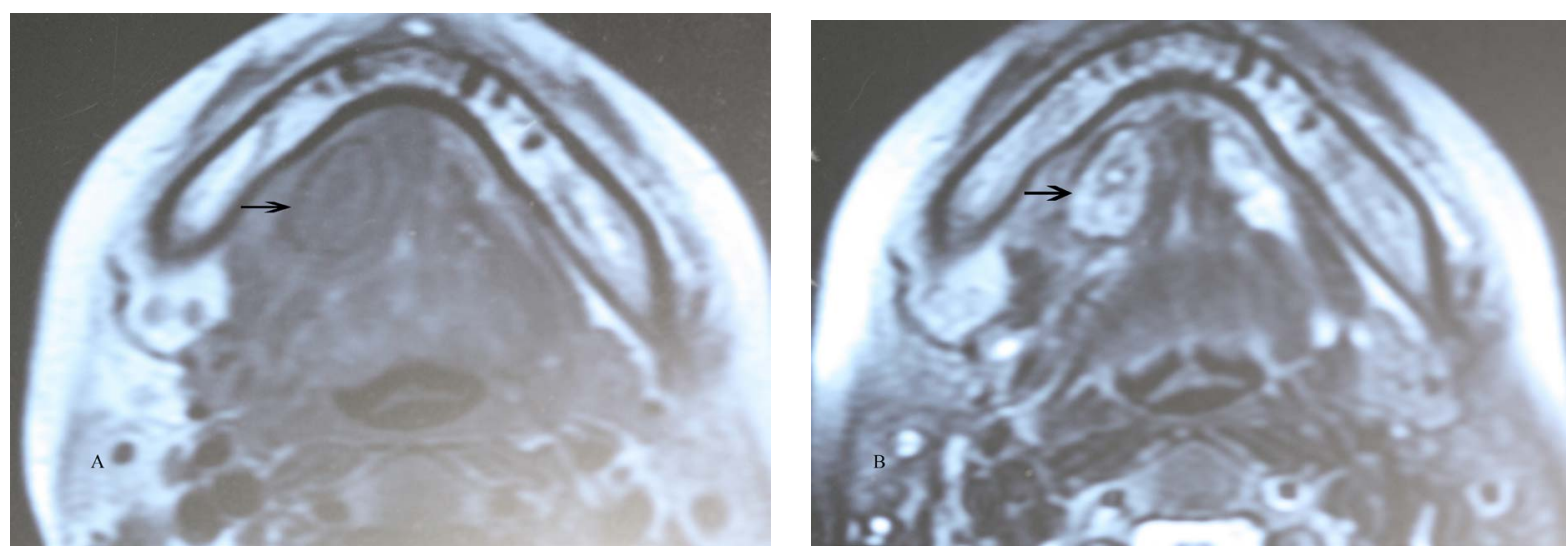

Figure 2. MRI showed a mass of clear boundary affected submandibular and sublingual region with low in density in T1 weighed MR image and mixed high-low in density in T2-weighed MR image (as arrow indicated).

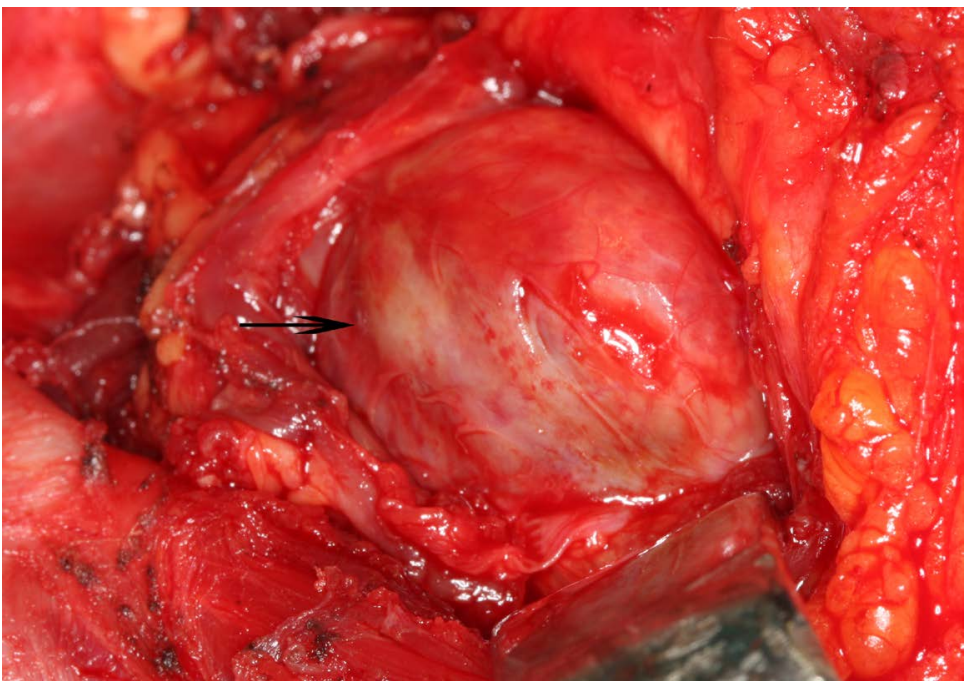

Figure 3. A well encapsulated vascular mass was encountered beneath the superficial layer of deep cervical fascia (as arrow showed). 


\section{Discussion}

IPEH can occur in any blood vessel in the body but most commonly it affects the skin and subcutaneous tissues of the fingers and trunk [4] [5]. IPEH is relatively uncommon in the region of head and neck. The most common site is the lower lip, followed by the tongue and the upper lip [1] [3] [4]. To date, there is only one document reporting a case which affects the right submandibular region [5].

Histologically IPEH is often mistaken to angiosarcoma. However, the lesion lacks cellular anaplasia and an infiltrative pattern of growth, both important features in angiosarcoma. Furthermore its intravascular location coupled with the lack of necrosis, pleomorphism, or atypical mitoses helped to differentiate it from angiosarcoma [2]. When the patient first came to our faculty, clinical characteristics mimicked malignant vascular lesions. However, no cell atypia or invasive behavior was observed. Another biopsy was made to clear the lesion. IPEH should be distinguished from hemangioma, vascular anomalies or mucocele when it affects the head-neck region. A histological review of 103 consecutive cases of vascular malformations of the oral cavity showed 6 cases of IPEH [3]. The surgeon and pathologist of local community hospital diagnosed the lesion as venous malformations (VMs) because of the atypical microscopic features and lack of knowledge of IPEH. However, there are some clinical, histological, and biological differences as well as imaging features between VMs and IPEH [5] [6]: 1) VMs often present at birth without a gender gap; while IPEH has a mean presentation at age 42.6 years with a slight female preponderance; 2) VMs are characterized by a soft, compressible, non-pulsatile tissue mass; while IPEH usually represents a firm or tender nodule or mass with slight elevation, rather sharp demarcation; 3) MRI imaging features for VMs includes high signal intensity on T2-weighted images, intermediate signal intensity on T1-weighted images; the imaging findings of our case showed mixed high-low density in an axial T2weighed image and low density in an axial T1-weighed image; 4) Histologically VMs are non-proliferative lesions that consist of dysplastic spongelike venous channels; the histological characteristic feature of IPEH is the presence of papillary endothelial proliferations confined within a vascular lumen.

Because of lack of specific clinical characteristics, the final diagnosis of IPEH must be realized only after the biopsy and microscopic examination. In this case the short time interval between the two biopsies revealed that the lesion was IPEH from the beginning but mistaken for venous malformations, as the incision biopsy material was inadequate or lack of knowledge about IPEH. This emphasizes the importance of adequate biopsies of vascular tumors and significance for oral pathologists and clinicians to be familiarized with this lesion. Inadequate biopsy material may mask the major lesion that lies in the deeper regions, as in this case, and may give rise to problems in managing the differential diagnosis and treatment, as VMs have been observed better results with sclerosing agent therapy. However, surgery is generally contemplated after sclerotherapy when treatment is incomplete or when an aesthetic prejudice requires correction, while the complete surgical excision is the best therapy for patients with IPEH [1] [5] [7].

That IPEH occurs more often in females than in males may indicate a hormonal influence. However, the pathogenesis remains unknown. IPEH is now accepted as a reactive proliferation of endothelial cells arising in an organizing thrombus, possibly related to trauma, which justifies the presence of these lesions on lip cheek or tongue, as these are the most commonly affected by trauma in oral region [3] [4]. The patient was unaware of any recent trauma to the submandibular and sublingual region, but thrombosis which IPEH maybe arise from were observed under microscope. IPEH is a relatively rare disease. Generally, the complete surgical excision in healthy margins is the best therapy for patients with IPEH, being both diagnostic and curative. Recurrence is unusual. In our case, Pingyangmycin intratumorally was given in the local hospital. However, right submadibular swelling was aggravated. The lesion was completely excised in our faculty according to the literatures published, and no recurrence was observed up to now.

IPEH is rare especially when affecting head-neck region. It is important for pathologists and clinicians to be aware of this lesion to prevent incorrect diagnosis and avoid aggressive treatment.

\section{Conflict of Interest}

The authors confirm that there is no conflict of interest in relation to this paper.

\section{References}

[1] Tosios, K., Koutlas, I.G. and Papanikolaou, S.I. (1994) Intravascular Papillary Hyperplasia of the Oral Soft Tissues: 
Report of 18 Cases and Review of the Literature. Journal of Oral and Maxillofacial Surgery, 52, 1263-1268. http://dx.doi.org/10.1016/0278-2391(94)90048-5

[2] Soares, A.B., Altemani, A., Furuse, C., Demasi, A.P., Gati, C., Nunes, N. and de Araújo, V.C. (2008) Intravascular Papillary Endothelial Hyperplasia: Report of 2 Cases and Immunohistochemical Study. Oral Surgery Oral Medcine Oral Pathoogy Oral Radiology Endodontics, 106, 708-711. http://dx.doi.org/10.1016/j.tripleo.2008.08.011

[3] de Courten, A., Küffer, R., Samson, J. and Lombardi, T. (1999) Intravascular Papillary Endothelial Hyperplasia of the Mouth: Report of Six Cases and Literature Review. Oral Disease, 5, 175-178. http://dx.doi.org/10.1111/j.1601-0825.1999.tb00086.x

[4] Matsuzaka, K., Koike, Y., Yakushiji, T., Shimono, M. and Inoue, T. (2003) Intravascular Papillary Endothelial Hyperplasia Arising from the Upper Lip. The Bulletin of Tokyo Dental College, 44, 55-59. http://dx.doi.org/10.2209/tdcpublication.44.55

[5] Kim, D., Israel, H., Friedman, M., Kuhel, W., Langevin, C.J. and Plansky, T. (2007) Intravascular Papillary Endothelial Hyperplasia Manifesting as a Submandibular Mass: An Unusual Presentation in an Uncommon Location. Journal of Oral and Maxillofacial Surgery, 65, 786-790. http://dx.doi.org/10.1016/j.joms.2005.11.095

[6] Dubois, J., Soulez, G., Oliva, V.L., Berthiaume, M.J., Lapierre, C. and Therasse, E. (2001) Soft-Tissue Venous Malformations in Adult Patients: Imaging and Therapeutic Issues. Radio Graphics, 21, 1519-1531. http://dx.doi.org/10.1148/radiographics.21.6.g01nv031519

[7] Murugaraj, V., Kingston, G.T., Patel, M. and Anand, R. (2010) Intravascular Papillary Endothelial Hyperplasia (Masson's Tumour) of the Oral Mucosa. British Journal of Oral and Maxillofacial Surgery, 48, e16-e17. http://dx.doi.org/10.1016/j.bjoms.2009.12.009 
Scientific Research Publishing (SCIRP) is one of the largest Open Access journal publishers. It is currently publishing more than 200 open access, online, peer-reviewed journals covering a wide range of academic disciplines. SCIRP serves the worldwide academic communities and contributes to the progress and application of science with its publication.

Other selected journals from SCIRP are listed as below. Submit your manuscript to us via either submit@scirp.org or Online Submission Portal.
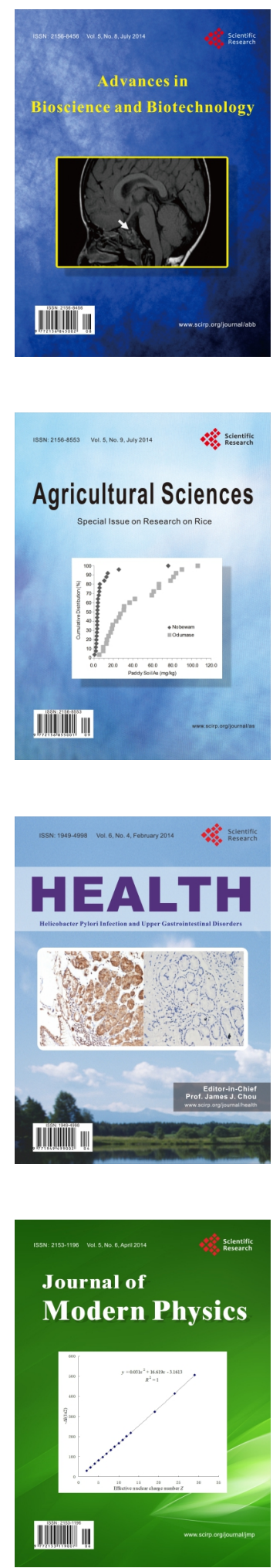
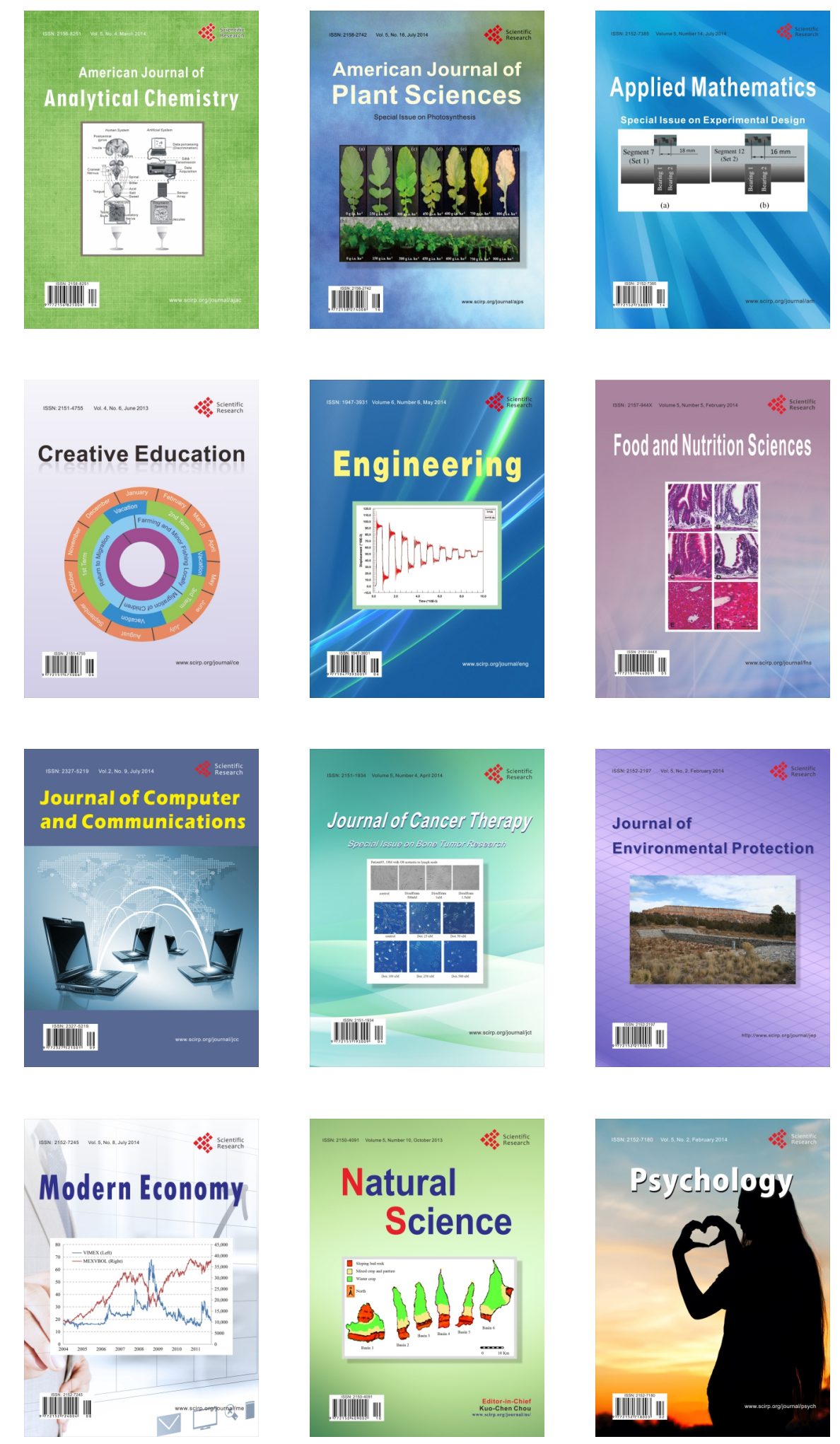